\title{
To merge or to license: implications for competition policy $^{\not 2}$
}

\author{
Ramon Fauli-Ollery and J oel Sandonis ${ }^{z}$ \\ J anuary $1^{\text {st }}, 2000$
}

\begin{abstract}
A bstract
The optimal merger policy when ex ciency gains are not merger speci ${ }^{-} \mathrm{c}$ but can also be achieved through licensing is derived in a di ßerentiated goods Cournot duopoly. We show that whenever both royalties and fees are feasible instruments to license technology, mergers should not be allowed, which 'ts the prescription of the U.S. Horizontal Merger Guidelines. When only one instrument is feasible, however, the possibility of licensing cannot be used as a de nitive argument against mergers.
\end{abstract}

Keywords: merger, licensing, optimal contracts, competition policy.

J.E.L. Classi' cation: L13, L41, D45.

This paper has been partially written while the second author was visiting the Kellogg Graduate School of Management at Northwestern University. We would like to thank R. Casadeus, M. Kamien, D. P \&rez-Castrillo and seminar participants at Northwestern University for helpful suggestions. Financial support from projects DGE S PB97-0603 and UPV 035.321-HB 159/ 98 is gratefully acknowledge.

y Universidad de Alicante. Departamento de Fundamentos del An $\$$ lisis E conmico. Campus de Sant Vicent. 03071 Alicante. Spain. e-mail: fauli@merlin.fae.ua.es

z Universidad del Palls Vasco. Departamento de Fundamentos del An\$lisis Econ\&mico. Avd. Lehendakari Aguirre 83. 48015 Bilbao. Spain. e-mail: jepsadij@bs.ehu.es 


\section{Introduction}

N owadays, companies all over the world seem to have an insatiable appetite for mergers, with the goal of capturing complementarities, scale economies, integrating technologies and production facilities and achieving cost e \pm ciencies. This phenomenon demands a severe control by antitrust authorities to prevent anticompetitive behaviors. Until 1997, Section 5 of the 1992 U.S Horizontal Merger Guidelines (HMG), prescribed to forbid mergers whenever the e \pm ciency gains were less than their competitive risks or whenever \equivalent or comparable savings can reasonably be achieved by the parties through other means". In A pril 1997, this section on etciencies was extended to explicitly include among them the possibility of licensing. ${ }^{1}$ This is probably due to the increasing importance played by licensing in the di ßusion of new technologies in the last few years. For example, A rora and Fosfuri (1998) document a widespread incidence of licensing in the chemical industry. A nand and K hanna (1997) report that licensing is also very common in biotechnology and ' ${ }^{-}$d that licensing has increased in frequency between 1990-1993 (the time period of their study). Finally, evidence of the importance of licensing in computers, automotive, biopharmaceuticals, engineering and electronics is also reported in di ßerent surveys.

In this paper we evaluate the accuracy of the HMG prescription. To address this issue, the optimal merger policy when licensing is an alternative to a merger to transfer a superior technology is derived. We focus on a simple case in which both instruments are assumed to allow the perfect and complete transmission of the innovation. In other words, we consider both instruments equivalent from a technological point of view, ignoring problems of asymmetric information between licensor and licensee, as well as the possibility that a merger can create synergies that could give a merger a technological advantage over licensing. Considering licensing and mergers technologically equivalent, while making the analysis tractable, will not signi ${ }^{-}$cantly a Rect the qualitative results we obtain. Its main consequence will be that, when deriving the optimal merger policy in this setting, we will never be too permissive

\footnotetext{
${ }^{1} \backslash$ The agency will not deem e \pm ciencies to be merger speci ${ }^{-} \mathrm{c}$ if they could be preserved by practical alternatives that mitigate competitive concerns, such as divestiture or licensing."
} 
with respect to mergers.

The crucial aspect we focus on in this work is that licensing and merging are not equival ent regimes with respect to their impact on competition. A merger eliminates competition but e \pm ciency gains are completely exploited by the emerging monopoly when deciding outputs. On the other hand, under licensing market competition remains but the licensee's output is distorted, as the optimal licensing contract always includes a royalty. We compare social welfare under both policies in a di ßerentiated goods Cournot duopoly, which allows us to derive the optimal merger policy, and to check whether that policy ${ }^{-}$ts the prescription of the HMG. We show that, regardless of the type of competition, the optimal merger policy ${ }^{-}$ts the prescription of the HMG whenever both ${ }^{-}$xed fees and royalties are feasible instruments to license the superior technology. Otherwise, we show that the HMG is too restrictive because it could lead to forbid welfare improving mergers. In particular, when royalties are not feasible due for example to lack of veri' ability of the licensee's output, the HMG is too restrictive because large enough innovations make licensing unpro ${ }^{-}$table for the patentee. On the other hand, if only royalties are feasible due for example to existing riskiness associated to the innovation that precludes the use of fees, the patentee tends to charge a greater royalty, distorting even more the licensee's output and thus additionally reducing welfare.

Regarding existing literature on mergers, Salant et al. (1983) showed that mergers can be unpro ${ }^{-}$table in a symmetric Cournot setting and Perry and Porter (1985) that e \pm ciency gains can make mergers pro ${ }^{-}$table. Regarding welfare consequences of mergers, Farrell and Shapiro (1990) derived conditions based on market shares of ${ }^{-} \mathrm{rms}$ under which a merger increases welfare. However, to the best of our knowledge, ours is the ${ }^{-}$rst paper that derives the optimal merger policy when licensing is a substitute of a merger to transfer a superior technology.

On the other hand, the licensing literature has mainly focused on the performance of ${ }^{-}$xed fees and royalties as instruments to market cost-reducing innovations. $\mathrm{K}$ amien and Tauman (1986) and Katz and Shapiro (1986), ignoring information problems, show that licensing by means of $a^{-}$xed fee is superior to licensing by means of a royalty for an external laboratory, 
in a homogeneous goods Cournot oligopoly. Muto (1993) extends those works to the case of B ertrand competition and shows that for the case of close substitute goods a royalty can be superior to a fee. On the other hand, for the case of an internal patentee, $K$ atz and Shapiro (1985) analyze - $x$ ed fees in a homogeneous goods Cournot duopoly, showing that licensing a cost-reducing innovation is not always pro ${ }^{-}$table for the patentee. Wang (1998) extends their analysis to the comparison between fees and royalties and shows that a royalty is always superior to a fee for the patentee. Finally, Faulf-Oller and Sandonls (1999) extend the set of feasible contracts to allow for the possibility that both fees and royalties can be simultaneously used and derive the optimal two-part tari ${ }^{\circledR}$ licensing contract in a di ßerentiated goods duopoly for both Cournot and Bertrand competition. Including asymmetric information problems, Gallini and Wright (1990), Macho-Stadler and P \&rez-Castrillo (1991) and M acho-Stadler et al. (1996) show that both fees and royalties should be included in the optimal licensing contracts. Royalties are useful either to signal good innovations or to separate the potential licensees that are willing to pay more for the innovation.

The remainder of the paper is organized as follows: Section 2 presents the model. Section 3 derives the optimal merger policy for the case of Cournot competition and analyzes under what circumstances it ${ }^{-}$ts the prescription of the HMG. Finally, a section with the main conclusions closes the paper.

\section{The model}

We consider two ${ }^{-}$rms, denoted by $i=1,2$, each producing a di ßerentiated good (goods 1 and 2 respectively). They face inverse demand functions given by:

$$
p_{i}=1 ; \quad x_{i} i^{\circ} x_{j} ; i ; j=1 ; 2 ; i \epsilon j ;
$$

where $^{\circ} 2[0 ; 1]$ and represents the degree of product di \&erentiation. Following Singh and Vives (1984), these demands come from the maximization problem of a representative consumer with utility separable in money $(m)$ given by:

$$
u\left(x_{1} ; x_{2}\right)=x_{1}+x_{2} i \frac{x_{1}^{2}}{2} i \frac{x_{2}^{2}}{2} i{ }^{\circ} x_{1} x_{2}+m:
$$


The direct demand functions are given by:

$$
x_{i}=\frac{1}{1+{ }^{\circ}} i \frac{p_{i}}{1 i^{\circ 2}}+{ }^{\circ} \frac{p_{j}}{1 i^{\circ 2}} ; i ; j=1 ; 2 ; i \in j:
$$

Firm 2 has constant unit production costs of $c_{2}: F$ irm 1 is assumed to have a patented process innovation that allows to produce good 1 at a lower marginal cost $c_{1}$, that we set, without loss of generality, to be zero. Two di ßerent mechanisms to transfer the superior technology to ${ }^{-} \mathrm{rm} 2$ are considered: a licensing agreement and a merger. B oth mechanisms are assumed to reduce the marginal cost of producing good 2 to zero, that is, we ignore problems of asymmetric information between the contracting parties in licensing agreements and the possibility that a merger creates synergies.

Depending on the size of the innovation we will distinguish between drastic and nondrastic innovations. We will call an innovation drastic when ${ }^{-} r m 1$ may monopolize its market. In particular, this is the case if $c_{2}>c_{2}^{M}$; where $c_{2}^{M}=\frac{2_{i}^{\circ}}{2}$ :

Let us de ${ }^{-}$ne the social welfare function as

$$
W\left(x_{1} ; x_{2}\right)=u\left(x_{1} ; x_{2}\right) ; \quad c_{1} x_{1} ; \quad c_{2} x_{2}:
$$

The timing of the game is the following:

In the " rst stage, the antitrust authority decides whether or not to allow mergers. In the second stage, the ${ }^{-}$rms have the possibility to merge (if allowed in the ${ }^{-}$rst stage), or to sign a licensing contract. Given this decision, market competition takes place in the third stage, with the cost functions inherited from the second stage. We solve by backwards induction, obtaining the subgame perfect $N$ ash equilibrium of the proposed game.

We will consider three di ßerent licensing scenarios: two-part tari ${ }^{(}(f ; r)$ licensing contracts, royalty $(r)$ contracts and fee $(f)$ contracts, where $f$ represents $a{ }^{\circ}$ at lump-sum license fee and $r$ represents a per unit of output fee (royalty). Scenario 2 arises when riskiness associated to the innovation precludes the use of fees. Scenario 3, when royalties are not feasible due, for example, to lack of veri ${ }^{-}$ability of the licensee's output. Otherwise, scenario 1 arises. The licensing game is modelled as follows: ' $r$ rst, the patentee makes a take-it-or-leave-it o Ber to ${ }^{-} \mathrm{rm} \mathrm{2}$; second, this ${ }^{-} \mathrm{rm}$ accepts or rejects the contract. We do not allow for negative 
fees because, otherwise, as argued by K atz and Shapiro (1985), contracts would include the possibility for the patent holder to \bribe(s) ${ }^{-} \mathrm{rm} 2$ to exit the industry... and would likely be held to be illegal by antitrust authorities." 2 It should be noted that the licensee's marginal cost whenever a royalty is included in the licensing contract (scenarios 1 and 2) is given by $r$ and thus, the patentee plays the role of a leader, as he determines the reaction function of the licensee by deciding the royalty to be included in the contract. On the other hand, under fee licensing (scenario 3) or under a merger, ' $r m$ 2's marginal cost becomes zero.

Next section derives the optimal merger policy under the three possible licensing scenarios.

\section{The optimal merger policy}

We start by calculating the third stage ${ }^{-} \mathrm{rms}^{\prime}$ Nash equilibrium outputs, pro ${ }^{-}$ts and total incomes, given that ${ }^{-} r m 2$ has accepted a $(f ; r)$ contract. They are given, respectively, by:

$$
\begin{gathered}
x_{1}(r)=\operatorname{minf} \frac{2 i^{\circ}(1 ; r)}{4 i^{\circ 2}} ; \frac{1}{2} g ; x_{2}(r)=\operatorname{maxf} \frac{2(1 ; r) i^{\circ}}{4 i^{\circ 2}} ; 0 g ; \\
1 / 4(r)=x_{1}(r)^{2} ; 1 / \mathbb{Q}(r)=x_{2}(r)^{2} ; \\
l_{1}(r ; f)=1 / 4(r)+r x_{2}(r)+f ; \quad i_{2}(r ; f)=1 / \mathbb{4}(r) i f:
\end{gathered}
$$

By substituting $C_{2}$ for $r$ in the above expressions, the equilibrium outputs and pro $^{-}$ts under the status quo situation are obtained. Notice that when ${ }^{-} \mathrm{rm} 2$ is not active, ${ }^{-} \mathrm{rm}$ one produces the monopoly output $\mathrm{x}_{1}=1=2$ :

Finally, we de ne industry outputs and pro ${ }^{-}$ts under a merger. They are given by:

$$
x_{1}^{m}=x_{2}^{m}=\frac{1}{2\left(1+{ }^{\circ}\right)} ; 1 / 4^{m}=\frac{1}{2\left(1+{ }^{\circ}\right)}:
$$

Notice that merging is al ways preferred to licensing by the ${ }^{-} r m s$ because while both policies transfer the superior technology a merger, in addition, eliminates market competition.

\footnotetext{
${ }^{2} \mathrm{~N}$ otice that we do allow for contracts including negative royalties. Nevertheless, for the case of substitute goods, it is never optimal for the patentee to charge a negative royalty. This would be the case, however, for complementary goods, that are not considered in this work.
} 
Therefore, if allowed by the antitrust authority, the ${ }^{-} \mathrm{rms}$ will always choose to merge. ${ }^{3}$

We start the analysis by scenario 1, comparing two-part tari ${ }^{\circledR}$ licensing with a merger.

\subsection{M erging vs. two-part tari ${ }^{\circledR}$ licensing}

First of all, two-part tari ${ }^{\circledR}$ licensing is always pro $^{-}$table for the patentee because it may always reproduce the status quo by setting a royalty that just equals the reduction in unit costs that the licensee achieves on account of the new technology. This would leave the licensee indi ßerent between licensing or not, and let the licensor enjoy the gains from the licensee's improved $e \pm$ ciency. ${ }^{4}$ On the other hand, two-part tari ${ }^{\circledR}$ licensing is also welfare improving because it never reduces competition, provided that the royalty cannot exceed $c_{2}$. Therefore, in order for the antitrust authority to prescribe when a merger should be allowed it has to compare the licensing policy and a merger from a social point of view.

First of all, we have to obtain the optimal two-part tari ${ }^{\circledR}$ licensing contract (the contract that maximizes the patentee's total income). As shown in Faulf-oller and Sandonils (1999) the optimal two-part tari ${ }^{\circledR}$ contract $(f ; r)$ always includes a positive royalty, and is given by:

$$
\begin{aligned}
& r^{\not}=\operatorname{minf} c_{2} ; r_{c}^{\infty} g ; \text { where } r_{c}^{\infty}=\frac{{ }^{\circ}\left(2 i^{\circ}\right)^{2}}{2\left(4 ; 3^{\circ} 2\right)} ; \\
& f^{x}=\operatorname{maxf} 1 / \mathbb{Q}\left(r_{c}^{0}\right) ; \quad 1 / \mathbb{Q}\left(C_{2}\right) ; 0 g:
\end{aligned}
$$

For the sake of completeness, the proof is included in the A ppendix.

Observe that for the case of homogenous products $\left({ }^{\circ}=1\right), r_{c}^{\infty}=c_{2}^{M}$; which implies that drastic innovations $\left(c_{2}, c_{2}^{M}\right.$ ) are not licensed (see Wang, 1998). However, whenever ${ }^{\circ}<1$; even drastic innovations are licensed because, in that case, $r_{c}^{\infty}<c_{2}^{M}$ :

\footnotetext{
${ }^{3}$ Because we are interested in the social welfare consequences of mergers, we will not enter into the analysis of how the merging ${ }^{-}$rms share monopoly pro $^{-}$ts. However, intuitively, the technologically superior - rm would not accept less than what she could guarantee under the optimal licensing contract and, the other ${ }^{-} \mathrm{rm}$, should receive not less than what she would receive in that case. Provided that monopoly pro ${ }^{-}$ts are never less than the joint pro ${ }^{-}$ts under the optimal licensing contract, a merger agreement would always be feasible.

${ }^{4}$ In fact, strictly speaking, two-part tari ${ }^{\circledR}$ licensing only guarantees non-negative pro ${ }^{-}$ts for the patentee because, as we will see later, for large enough innovations particular cases exist such that the patentee is indi Rerent between licensing and the status quo.
} 
In order to prescribe when mergers should be allowed in this scenario, let us ${ }^{-}$rst denote by $\mathrm{W}^{\mathrm{m}} ; \mathrm{W}^{\mathrm{u}}$ and $\mathrm{W}^{\mathrm{r}}$ social welfare under a Merger, under the optimal Unrestricted royalty $\left(r^{\not}=r_{c}^{0}\right)$ and under the optimal Restricted royalty $\left(r^{\not}=c_{2}\right)$. They are de ned by:

$$
W^{m}=u\left(x_{1}^{m} ; x_{2}^{m}\right) ; W^{u}=u\left(x_{1}\left(r_{c}^{g}\right) ; x_{2}\left(r_{c}^{g}\right)\right) ; W^{r}=u\left(x_{1}\left(c_{2}\right) ; x_{2}\left(c_{2}\right)\right):
$$

Next proposition derives the optimal merger policy for scenario 1.

Proposition 3.1. When two-part tari ${ }^{\circledR}$ licensing contracts are feasible, mergers should never be allowed.

Proof. First, for $c_{2} \cdot r_{c^{\prime}}^{\infty}$ a merger is socially preferred to a royalty regime if $W^{m} i W^{r}$ is positive. Directly comparing the corresponding expressions results in that $\mathrm{W}^{\mathrm{m}}, \mathrm{W}^{\mathrm{r}}$ if and only if $c_{2}, c_{2}^{m c}$, where $c_{2}^{m c}=\frac{8_{i} 6^{\circ 2}+2^{\circ} i_{i} \overline{2\left(4_{i}{ }^{\circ 2}\right)^{2}\left(2+4^{\circ} i^{\circ{ }^{\circ}} i 3^{\circ} 3\right)}}{2\left(i 4_{i} 4^{\circ}+3^{\circ} 2+3^{\circ}\right)}$.

Now, comparing $c_{2}^{m c}$ and $r_{c}^{\Phi_{c}}$ we obtain $c_{2}^{m c}, r_{c}^{\infty}$, which implies that for $c_{2}<r_{c}^{\infty}$, licensing is always socially preferred to a merger. Second, for $c_{2}, r_{c}^{\infty}$, welfare under royalty licensing is constant in $c_{2}$ : As welfare under a merger does not depend on $c_{2}$, in order to compare both regimes in this region we just need to know the sign of $W^{m} i W^{r}$ evaluated in $c_{2}=r_{c}^{\infty}$. $B$ ut we know that at this point licensing is socially preferred to a merger, which closes the proof.

The result in Proposition 3.1 exactly ${ }^{-}$ts the prescription of the U.S. merger guidelines: when the ex ciency gains are not merger speci ${ }^{-} \mathrm{c}$ and can be also attained through licensing, mergers should be forbidden. Notice that the result arises in a context in which both ${ }^{-} x$ ed fees and royalties are feasible. This requires output to be veri ${ }^{-}$able and uncertainty low enough as not to preclude the use of royalties and - xed fees, respectively. We will next proceed to derive the optimal merger policy in scenarios 2 and 3.

\subsection{M erging vs. royalty licensing}

As licensing by means of a royalty is always pro- table for the licensor as well as welfare improving, in order to prescribe when a merger should be allowed in this scenario it is su \pm cient to compare royalty licensing and a merger from a social point of view. 
Next proposition shows the optimal royalty contract (the contract that maximizes the patentee's total income).

Proposition 3.2. The optimal royalty contract is given by:

$$
r^{\sharp}=\operatorname{minf} c_{2} ; r_{c}^{0} g ; \text { where } r_{c}^{0}=\frac{\left(2 i^{\circ}\right)\left(4+2^{\circ} i^{\circ 2}\right)}{2\left(8 i 3^{\circ} 2\right)} \text { : }
$$

Proof. The optimal royalty solves:

$$
\begin{aligned}
& \max _{r} f \frac{1}{4}(r)+r x_{2}(r) g \\
& \text { s:t: } r \cdot c_{2}:
\end{aligned}
$$

Direct resolution of this problem results in the optimal contract shown in the proposition.

Next proposition derives the optimal merger policy for scenario 2 by direct comparison of welfare under both regimes:

P roposition 3.3. When only a royalty can be included in the licensing contract, a threshold value $c_{2}^{m c}$ exists such that a merger should be allowed if and only if $c_{2}, c_{2}^{m c}$.

Proof. First, observe that for $c_{2} \cdot r_{c}^{0}$, we are in the case of restricted royalty and in this case we compute $\mathrm{W}^{\mathrm{m}} \mathrm{i} \mathrm{W}^{\mathrm{r}}, 0$ if $\mathrm{c}_{2}, \mathrm{c}_{2}^{\mathrm{mc}}$, where $c_{2}^{\mathrm{mc}}$ has been de ned in Proposition 3.1 . Second, comparing $c_{2}^{m c}$ and $r_{c}^{0}$ we obtain that $c_{2}^{m c} \cdot r_{c}^{0}$ and $c_{2}^{m c} \cdot c_{2}^{M}$. This implies that for $c_{2}<c_{2}^{m c}$, licensing is socially preferred to a merger and for $c_{2}, c_{2}^{m c}$ a merger is socially preferred to licensing.

This proposition shows that licensing by means of a royalty is not always socially preferred to a merger. The reason is that the patentee must use the only feasible instrument (the royalty) not only to soften competition but also to appropriate the surplus generated by the superior technology, which results in a higher royalty, in a higher distortion in the licensee's output, and lower social welfare.

\subsection{M erging vs. ${ }^{-}$xed fee licensing}

Licensing by means of a fee is pro ${ }^{-}$table whenever it increases industry pro ${ }^{-}$ts. As shown by Katz and Shapiro (1985) for the case of homogeneous goods, for large enough innovations 
the e \pm ciency gains can be more than compensated by the rent dissipation e ${ }^{\circledR e c t}$, making duopoly pro ${ }^{-}$ts decrease. In these cases, licensing will not occur and a merger becomes the only alternative to transfer technology. Next proposition characterizes the conditions under which ${ }^{-}$xed fee licensing is pro ${ }^{-}$table for the patentee.

Proposition 3.4. A threshold value $c_{2}^{L}$ exists such that if ${ }^{\circ} \cdot{ }^{\bullet}$, licensing by means of a fee is always pro ${ }^{-}$table; if ${ }^{\circ}>^{\bullet}$; it is pro table if and only if $C_{2} \cdot C_{2}^{L}$; where ${ }^{*}=0: 82$ :

Proof. Directly comparing industry pro ${ }^{-}$ts under fee licensing with the status quo situation, we obtain that $1 / 4(0)+1 / \mathbb{4}(0), 1 / 4\left(c_{2}\right)+1 / \mathbb{Q}\left(c_{2}\right)$ if either ${ }^{\circ} \cdot{ }^{2}$; or if ${ }^{\circ}>{ }^{*}$ and $c_{2} \cdot c_{2}^{L}$, where $C_{2}^{L}=\frac{2\left(4 \mathrm{i} 4^{\circ}+{ }^{\circ 2}\right)}{4+{ }^{\circ} 2}$

When the goods are close substitutes $\left({ }^{\circ}>0: 82\right)$, licensing is pro table only for small innovations. Otherwise $\left({ }^{\circ} \cdot 0: 82\right)$, licensing is pro ${ }^{-}$table regardless of the size of the innovation. This result is very intuitive: when the goods are very di ßerentiated, market competition is not intense and, therefore, the e \pm ciency gains more than compensate the rent dissipation e ßect produced by the license, making licensing always pro ${ }^{-}$table.

In the "rst stage of the game, the antitrust authority has to decide whether or not to allow mergers. We have to take into account that licensing by means of a fee is always socially preferred to a merger because, whereas both regimes achieve the same e \pm ciency gain a merger, additionally, erodes competition. Therefore, mergers should be allowed whenever licensing is not pro table for the patentee and a merger improves welfare with respect to the technological status quo. Next proposition compares social welfare under a merger and under the status quo situation.

Proposition 3.5. A threshold value $c_{2}^{m}$ exists such that regardless of the degree of product di ßerentiation, a merger is socially pro table if and only if $c_{2}, c_{2}^{m}$.

Proof. Direct comparison of welfare under the two regimes results in the proposition, where

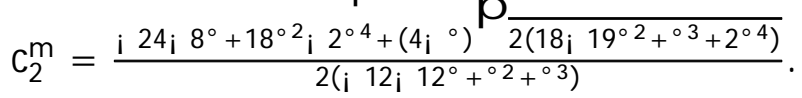

The above proposition shows that for large enough innovations and regardless of the degree of product di ßerentiation, the e \pm ciency gains attained through a merger compensate for 
its anticompetitive eßect, thus making mergers socially desirable. Observe that Proposition 3.5 can be seen as the optimal merger policy when the e \pm ciency gains attained through a merger are merger speci ${ }^{-} \mathrm{c}$.

Next proposition combines Propositions 3.4 and 3.5 to derive the optimal merger policy for scenario 3.

Proposition 3.6. When only a fee can be included in the licensing contract, mergers should be allowed if and only if ${ }^{\circ}>^{*}$ and $c_{2}, c_{2}^{L}$ :

Proof. Whenever licensing is not privately pro table and mergers are socially preferred to the status quo, mergers should be allowed. This proposition just brings together the corresponding conditions from the two propositions above, taking into account that $c_{2}^{L}$. $c_{2}^{m}:$

Summarizing, from the optimal merger policies derived in Propositions 3.1, 3.3 and 3.6, an interesting policy implication can be derived. When licensing is an alternative to a merger for (perfectly) transferring technology, a more restrictive optimal merger policy is called for. This argument seems to be present in the HMG, that prescribes to forbid mergers whenever the ex ciency gains can be alternatively achieved through licensing. The optimal merger policy derived above ${ }^{-}$ts that prescription only when both ${ }^{-}$xed fees and royalties are feasible instruments to license the superior technology. Otherwise, the possibility of licensing cannot be used as a de nitive argument against mergers. In particular, it may be too restrictive because it may lead to forbid welfare improving mergers: in scenario 2 , it may occur because the patentee imposes a high royalty that distorts the licensee's output a lot and reduces welfare. On the other hand, in scenario 3 because, as Proposition 3.4 shows, fee licensing is not always pro ${ }^{-}$table and, in these cases, a merger is the only eßective instrument to transfer technology. 


\section{Conclusions}

The traditional merger policy analysis prescribes to allow mergers if and only if e \pm ciency gains compensate their impact on competition. In this paper, we extend this analysis by considering also the existence of an alternative instrument that may allow " rms to attain those e \pm ciencies, namely, licensing. In this case, a more restrictive merger policy is called for. The 1992 U.S. Horizontal M erger Guidelines was revised in 1997 to incorporate this idea, and it prescribes to forbid mergers whenever e \pm ciency gains are not merger speci ${ }^{-} \mathrm{c}$, but can also be achieved through licensing. In this work, we have shown that the prescription of the HMG is too restrictive. In particular, for large innovations mergers tend to be superior to licensing: when royalties are not feasible, it is true because large innovations make licensing unpro $^{-}$table and, at the same time, make mergers socially desirable; on the other hand, when royalties are feasible, because for large innovations the patentee tends to impose high royalties, reducing total output and welfare.

In absence of licensing, the traditional merger policy is more restrictive the less di Rerentiated the goods are. This is still true when royalties are feasible. When only fees are feasible, however, the result is reversed: mergers should be allowed only when the goods are close substitutes. The reason for this counterintuitive result is that what determines the merger policy in this case is whether licensing is pro table or not. It turns out that it is not pro' table when goods are close substitutes.

Finally, an interesting extension of the model is to derive the optimal merger policy for the case of B ertrand competition. This is in fact work in progress. The results obtained in B ertrand are qualitatively similar to those in Cournot. They incorporate, however, the fact that Bertrand competition is more intense, which implies ${ }^{-}$rst, that the licensor tends to impose greater royalties in order to soften competition and, second, that mergers are more anticompetitive. While under Cournot licensing is always pro ${ }^{-}$table for the patentee, under Bertrand competition and even when both instruments are feasible, for large enough inno-

vations licensing becomes non-pro ${ }^{-}$table for the patentee, that uses the royalty to keep the other ${ }^{-} r m$ out of the market. In these cases, a merger becomes the only e ${ }^{\circledR e c t i v e ~ i n s t r u m e n t ~}$ 
to transfer the superior technology and thus, it should be allowed whenever it is welfare improving.

\section{A ppendix}

Derivation of the optimal two-part tari ${ }^{\circledR}$ licensing contract

The optimal two-part tari ${ }^{\circledR}$ licensing contract solves:

$$
\begin{gathered}
\max _{r ; f} f 1 / \mathbb{4}(r)+r x_{2}(r)+f g \\
\text { s:t: } f=1 / \mathbb{\Psi}(r) i^{1 / \mathbb{Q}(}\left(c_{2}\right) \\
f, 0:
\end{gathered}
$$

This program can be rewritten in a simpli ${ }^{-}$ed way. As the ${ }^{-}$rst constraint is always binding, it can be substituted in the objective function and the second constraint can be replaced with $r \cdot c_{2}$; that guarantees that the fee is never negative. The maximization problem thus becomes:

$$
\begin{aligned}
& \max _{r} f 1 / 4(r)+r x_{2}(r)+1 / \mathbb{4}(r) \text { i } 1 / \mathbb{2}\left(c_{2}\right) g \\
& \text { s:t: } \quad r \cdot c_{2}:
\end{aligned}
$$

Solving this program directly results in the optimal contract shown in the proposition.

\section{R eferences}

A rora, A. and Fosfuri, A., 1998, Licensing in the chemical industry, forthcoming, Stanford Technology Law Review.

A nand, B.N. and K hanna, T., 1997, Intellectual property rights and contract structure, W P 97-016, Harvard Business School.

Calvert, R ., 1964, The encyclopedia of patent practice and invention management. New York: Reinhold.

Farrell, J . and Shapiro, C., 1990, Horizontal mergers and equilibrium analysis, A merican E conomic R eview 80, 107-126. 
Faulf-oller, R. and Sandonls, J ., 1999, Optimal two-part tari ${ }^{\circledR}$ licensing contracts in a di ßerentiated goods duopoly, working paper, University of Alicante, Spain.

Gallini, N. and Wright, B., 1990, Technology transfer under asymmetric information, Rand J ournal of Economics 21 (1), 147-160.

K amien, M. and Tauman, Y ., 1986, Fees versus royalties and the private value of a patent, Quarterly J ournal of Economics, 101, 471-491.

Kamien, M., 1992, Patent Licensing. In: Aumann, R. J., Hart, S. (eds), Handbook of Game Theory, chapter 11.

Katz, M. and Shapiro, C., 1985, On th licensing of innovations. Rand J ournal of E conomics, $16,504-520$.

K atz, M. and Shapiro, C., 1986, How to license intangible property, Quarterly J ournal of E conomics, 101, 567-590.

M acho-Stadler, I. and D. P rez-Castrillo, 1991, Contracts de licence et asym trie d'information, A nnales d'E conomie et de Statistique, 24, 189-204.

Macho-Stadler, I., MartInez-G iralt, X. and P \&rez-Castrillo, D., 1996, The role of information in licensing contracts design, Research Policy 25, (1), 25-41.

Muto, S., 1993, On licensing policies in Bertrand competition, Games and Economic B ehavior 5, 257-267.

Perry, M . and Porter, R ., 1985, Oligopoly and the incentive for horizontal merger, A merican E conomic Review 75, 220-227.

Rostocker, M., 1984, A survey of corporate licensing. IDEA, 24, 59-92.

Salant, S., Switzer, S. and Reynolds, S., 1983, L osses from horizontal merger: the e®ects of an exogenous change in industry structure on Cournot-N ash equilibrium, Q uarterly J ournal of E conomics 98, 185-199.

Singh, V. and Vives, X., 1984, P rice and quantity competition in a di ßerentiated duopoly, R and J ournal of Economics 15, 546-554.

Wang, X., 1998, Fees vs. royalty licensing in a Cournot duopoly model, Economics Letters 60, 55-62. 